\section{RESPONSE}

\section{New policy may be in order}

\section{Stephen M. Dempsey, DVM}

The regulations are relatively silent on the issue of IACUC reappointment. While the new president of Great Eastern will serve as the CEO, his or her predecessor's appointments to the IACUC do not expire at the end of her term. Great Eastern's duly constituted IACUC does not require reappointment by the new president, unless that individual specifically wants to make some changes in the Committee's membership.

Under the AWRs, the CEO is authorized to appoint an IO and delegate all or some of the CEO's responsibilities for compliance with the AWRs to that individual. The one caveat is that the person serving as the IO does have to be authorized to legally commit the institution to compliance with requirements of the AWRs. When the new president takes over, it would be prudent for that individual to appoint or re-appoint an IO because of the role that the IO plays in taking on delegated responsibilities and actions, for which the president/CEO is ultimately responsible. Depending on the institution and president/CEO, the responsibility for appointment of IACUC members can be one of the delegated responsibilities given to the IO.

Although not required under current animal welfare regulations, it would be advisable to consider developing an institutional policy or procedure regarding the appointment of IACUC members, their terms, and the survivability of their appointment

\title{
A word from OLAW and USDA
}

In response to the issues raised in this scenario, the Office of Laboratory Animal Welfare (OLAW) and the United States Department of Agriculture, Animal and Plant Health Inspection Service, Animal Care (USDA/APHIS/AC) offer the following clarification and guidance:

The primary questions posed in the scenario are (1) whether the new Chief Executive Officer (CEO) will have to reappoint the Institutional Official (I0) or the IACUC, and (2) whether under the Animal Welfare Regulations (AWRs), the CEO can delegate authority to appoint the IACUC to the IO or someone else.

The Public Health Service Policy on Humane Care and Use of Laboratory Animals (PHS Policy) does not prescribe administrative procedures for appointments of IOs or CEOs, nor does it require that IACUCs appointed by designated IOs be reappointed by successor IOs. Section IV.F.1.b of the PHS Policy, however, does require IACUCs, through their IOs, to report "any change in the description of the program for animal care and use as required by IV.A.1.a.-I. of this Policy ${ }^{1 "}$ in writing to OLAW at least once every twelve months (that is, in the institutional Annual Report). The appointment of a new CEO and/or IO qualifies for reporting because it represents a change in the "lines of authority and responsibility for administering the program and ensuring compliance with this Policy ${ }^{1 "}$ described in the institution's previously approved Assurance and must therefore be re-evaluated by OLAW.

Likewise, in promulgating regulations for the 1985 amendments to the Animal Welfare Act (AWA), it was evident to USDA that rigid administrative requirements would be inappropriate given the diverse nature of research facilities. Rather, institutions should be permitted to develop procedures that satisfy the requirements and correspond to their operations ${ }^{2}$. There is no regulatory requirement for reappointment of IACUC members. The Research Facility Inspection Guide directs inspectors to look for some form of verification of the member's appointment; for example, a periodic letter/memo of reappointment may be appropriate if the institution has defined term limits for its members ${ }^{3}$.

Guidance previously issued by OLAW states that "the I0 signs the Assurance and is the person in the organization with the administrative and operational authority to commit institutional resources to ensure that the animal care and use program will comply with the requirements of the PHS Policy 4 ." It also explains that "the PHS Policy requires the CEO to appoint the IACUC in accord with specified qualifications and membership criteria, although the CEO may delegate this authority in writing," and recognizes that "in some institutions, the IO and the CEO may be one and the same, whereas in other institutions, particularly large ones, the CEO may be further removed from the day-to-day program oversight ${ }^{4}$."

USDA also allows the CEO of the research facility, in accordance with their charter and bylaws, to delegate his or her responsibility under the $\mathrm{AWA}^{5}$. This is considered to be an internal institutional matter. The term 'Institutional Official,' as added to the regulations in 1989, can refer to either the CEO or another responsible official authorized to legally bind the facility ${ }^{6}$.

1. Public Health Service. Policy on Humane Care and Use of Laboratory Animals A.3.a (US Department of Health and Human Services, Washington, DC, 1986; reprinted 2002).

2. USDA APHIS. Final Rules: Animal Welfare; 9 CFR Parts 2 and 3. Federal Register 54(168), 36123-36163 (31 August 1989).

3. USDA APHIS. Animal Care Resource Guide, Research Manual. http://www. aphis.usda.gov/ac/researchguide.html

4. National Institutes of Health, Office of Extramural Research. PHS Policy on Humane Care and Use of Laboratory Animals. Frequently Asked Questions, Institutional Responsibilities, Question No. 5. http://grants.nih.gov/ grants/olaw/faqs.htm\#instresp_5.

5. USDA APHIS. Proposed Rules: Animal Welfare; 9 CFR Part 2. Federal Register 54(49), 10835-10954 (15 March 1989).

6. USDA APHIS. Final Rules: Animal Welfare; 9 CFR Part 1. Federal Register 54(168), 36112-36123 (31 August 1989).

Patricia Brown, VMD, MS, DACLAM

Acting Director

OLAW, OER, OD, NIH, HHS

Chester Gipson, DVM

Deputy Administrator

USDA, APHIS, AC 
despite changes of the CEO or the IO. A separate policy for the appointment of the IO should also be developed. That policy should stipulate what responsibilities and actions have been delegated by the CEO and include some statement regarding appointment or reappointment at the discretion of a new or interim CEO. The existence of such policies will help to obviate any questions regarding these appointments.

Finally, it is important to remember that any change to the CEO or IO must be reported to the USDA Animal Care Regional Office within ten days of its occurrence.

Dempsey is Assistant Vice Chancellor for Research and University Attending Veterinarian, North Carolina State University, Raleigh, NC. The author acknowledges input from the Veterinary Staff of the Laboratory Animal Resources department of the North Carolina State University College of Veterinary Medicine, including Drs. Richard Fish (Director), Melanie Rembert (Assistant Director), and Karen Taylor (Assistant Professor).

\section{RESPONSE}

\section{No change in order}

\section{Erin Hutteman, AAS, BS, RLATG}

In this scenario, the outgoing $\mathrm{CEO}$ of Great Eastern appointed the IO, who then appointed each member of the IACUC. The Guide states that "the size of the institution and the nature and extent of research, testing, and education programs will determine the number of members of the committee and their terms of appointment ${ }^{1}$." If the Great Eastern CEO adhered to the regulations and appointed the $\mathrm{IO}$ and the IACUC members for certain term periods, then they would not have to be reappointed by the new president of the university. Of course, at the end of their appointed term, the IO and IACUC member could be reappointed if they wished to continue serving.
Daniels is correct that the AWRs state that the CEO appoints the IACUC, but the law does not go into detail as to how an institution handles changes in leadership, except that such changes of operation must be reported to an Animal Care Regional Director. The AWRs defines the IO as someone who is authorized to legally commit on behalf of the research facility. Since the AWRs do not specifically address the CEO or appointment of an IO, one might indeed conclude that the CEO can delegate the appointment of the IACUC to another individual within the institution who can legally commit for the facility.

1. Institute for Laboratory Animal Research, National Research Council. Guide for the Care and Use of Laboratory Animals 8 (National Academy Press, Washington, DC, 1996).

Hutteman is Research and Training Coordinator, UCAR, University of Rochester, Rochester, NY. 